Copyright C1997, American Institute of Aeronautics and Astronautics, Inc.

AIAA Meeting Papers on Disc, January 1997

A9715480, AIAA Paper 97-0419

\title{
Measured spacecraft dynamic effects on atmospheric science instruments
}

\author{
Stanley E. Woodard \\ NASA, Langley Research Center, Hampton, VA
}

David A. Gell

Michigan Univ., Ann Arbor

Richard R. Lay

JPL, Pasadena, $C A$

\begin{abstract}
AIAA, Aerospace Sciences Meeting \& Exhibit, 35th, Reno, NV, Jan. 6-9, 1997
On September 1991, NASA launched the Upper Atmosphere Research Satellite. In addition to its atmospheric science mission, spacecraft dynamic effects on science measurements were analyzed. The investigation included two in-flight experiments to determine how each on-board instrument, subsystem and environmental disturbance contributed to the spacecraft dynamic response and how these disturbances affected science measurements. Three case studies show the impact of spacecraft dynamic response on science measurements. (1) Correlation of independent atmospheric meridional wind data taken by two instruments with the spacecraft dynamic response demonstrated that excessive vibration (exceeding instrument pointing requirements) resulted in wind measurement disagreement. (2) Solar array disturbances produced a spacecraft response signature on radiometer measurements, demonstrating that if an instrument has sufficient spatial and temporal resolution, spacecraft dynamic response impacts measurements. (3) Correlation of an instrument's fine sun sensor data and $\mathrm{CO} 2$ measurements demonstrated the effect of temporal and spatial sampling resolution and active pointing control on science measurements. (Author)
\end{abstract}




\section{AIAA-97-0419.}

\section{MEASURED SPACECRAFT DYNAMIC EFFECTS ON ATMOSPHERIC SCIENCE INSTRUMENTS.}

\author{
Stanley E. Woodard* \\ NASA Langley Research Center \\ Hampion, VA \\ David A. Gell ${ }^{\dagger}$ \\ University of Michigan \\ Ann Arbor, MI \\ Richard R. Lay \\ Jet Propulsion Laboratory \\ Pasadena, CA
}

\begin{abstract}
On September 1991, NASA launched the Upper Atmosphere Research Satellite. In addition to its atmospheric science mission, spacecraft dynamic effects on science measurements were analyzed. The investigation included two in-flight experiments to determine how each on-board instrument, subsystem and environmental disturbance contributed to the spacecraft dynamic response and how these disturbances affected science measurements. Three case studies are presented which show the impact of spacecraft dynamic response on science measurements. In the first case, correlation of independent atmospheric meridional wind measurements taken by two instruments with the spacecraft dynamic response demonstrated that excessive vibration (exceeding instrument pointing requirements) resulted in wind measurement disagreement. In the second case, solar array disturbances produced a spacecraft response signature on radiometer
\end{abstract}

Copyright( 1997 by the American Institute of Aeronautics and Astronautics, Inc. No copyright is asserted in the United States under Title 17, U. S. Code. The U.S. Government has royalty-free license to exercise all rights under the copyright claimed herein for Governmental Purposes. All other rights are reserved by the copyright owner.

* Senior Research Engineer, Structural Dynamics Branch, Structures Division, Member AIAA.

' Senior Research Associate, Space Physics Research Laboratory, Department of Atmospheric, Oceanic and Space Sciences.

Project Engineer, Microwave Limb Sounder Team. measurements. The signaturc cxplicitly demonstrated that if an instrument has sufficient spatial and temporal resolution, spacecraft dynamic response could impact measurements. In the final case, correlation of an instrument's fine sun sensor data and $\mathrm{CO}_{2}$ measurcments demonstrated the effect of temporal and spatial sampling resolution and active pointing control on science measurements. The sun sensor had a frequency modulated characteristic due to spacecraft vibration and the periodic scanning of another instrument which was not present on the $\mathrm{CO}_{\text {? }}$ measurements.

\section{Nomenclature}

$\begin{array}{ll}\text { CLAES } & \begin{array}{l}\text { Cryogen Limb Array Etalon } \\ \text { Spectrometer }\end{array} \\ \text { HALOE } & \text { Halogen Occultation Experiment } \\ \text { HGA } & \text { High Gain Antenna } \\ \text { HRDI } & \text { High Resolution Doppler Imager } \\ \text { IM } & \text { Instrument Module } \\ \text { ISAMS } & \text { Mesospheric Sounder } \\ \text { MLS } & \text { Microwave Limb Sounder } \\ \text { SSPP } & \text { Solar Stellar Pointing Platform } \\ \text { UARS } & \text { Upper Atmosphere Research Satellite } \\ \text { WINDII } & \text { Wind Imaging Interferometer } \\ \text { ZEPS } & \text { Zenith Energetic Particle System }\end{array}$

\section{Introduction}

Multi-payload spacecraft offer both temporal and spatial co-registration of in-flight observations. However, when the spacecraft has multiple gimballed instruments and elastically flexible appendages, each instrument produces a disturbance which impacts the line-of-sight pointing of the other on-board instruments. ${ }^{1-7}$ Thus, spacecraft dynamic response to the multiple disturbances can cause measurement errors which directly impact science data analyses. If the science measurement history and the dynamic response history are available for correlation, the spacecraft response signature on the science data is readily apparent. Otherwise, the dynamic response influence upon the science data must be inferred from other observations. This paper presents results from three case studies using the Upper Atmosphere Research Satcllitc (UARS), launched September 12, 1991, which demonstrated the impact that spacecraft dynamic response had on the subsequent science measurements and analyses.

1

American Institute of Acronautics and Astronautics 
The goal of UARS was to carry out the first systematic, comprehensive study of the stratosphere and to furnish new data on the mesosphere and thermosphere. UARS provided critical data on the chemical composition of the upper atmosphere, particularly the structure of the Earth's protective ozone layer in the stratosphere. This satellite mission was the first element of a long-term national program to study global atmospheric change. Measurements taken with four of the ten UARS science instruments were used in the three aforementioned case studies.

Following an overview of the UARS spacecraft, the three case studies are presented. The first case study examined the role that spacecraft dynamic response had on fixed line-of-sight pointing, target tracking, and measurements taken by two instruments when one instrument's jitter requirement was exceeded. Jitter is the angular excursion of an instrument's line-of-sight in a reference time interval (such as a sampling time pcriod). In the first case, the High-Resolution Doppler Imager (HRDI) and the Wind Imaging Interferometer (WINDII) meridional wind speed measurements were correlated with spacecraft roll gyro data. The correlation of the independent wind measurements with the spacecraft dynamic response demonstrated that excessive vibration (exceeding instrument pointing requirements) resulted in wind measurement disagreement. The second case study used results from an experiment performed on UARS on September 17, 1993. The experimental objective was to determine if spacecraft dynamic response affected measurements taken by an instrument with spatial resolution and sampling interval sufficient enough to discern the contributions due to the response. The Microwave Limb Sounder (MLS) antenna was controlled such that it maintained a fixed line-of-sight pointing to allow cxamination of the influcnce of the spacecraft response on its radiance measurements. MISS maintaining a fixed line-of-sight pointing emulated the WINDII instrument. The solar array disturbances produced a spacecraft response signature on MLS radioneter measurements. The signature explicitly demonstrated that if an instrument has sufficient spatial and temporal resolution, spacecraft dynamic response could impact measurements.

The third case demonstrated that the solar array vibration and motion of the High Resolution Doppler Imager (HRDI) perturbed the Halogen Occultation Experiment (HALOE) pointing. These results were derived from an experiment performed on UARS on May 1, 1992. The correlation of fine sun sensor data and $\mathrm{CO}_{2}$ measurements demonstrated the effect of temporal and spatial sampling resolution and active pointing control on science measurements. The sun sensor had a frequency modulated characteristic due to spacecraft vibration and the periodic scanning of another instrument which was not present on the $\mathrm{CO}_{2}$ measurements. Following the third case study are concluding remarks.

\section{UARS Overview}

The UARS observatory (Fig. 1) included ten science instruments, a high gain antenna for communication links, a Solar Stellar Pointing Platform (SSPP) that carried three of the instruments and an attitude control system. In addition to the suite of science instruments, UARS had a solar array consisting of six panels and an extensional boom which were excited by disturbance sources on-board the spacecraft. On-board disturbances were caused by UARS five gimballed instruments and subsystems, attitude control reaction wheels, the propulsion subsystem, and thermal elastic bending of the solar array as the spacecraft passed through the Earth's terminator. These disturbances could affect the precision pointing of the remote sensing instruments and co-registration of measurements. To produce an accurate measurement, each instrument must have had its line-of-sight pointing jitter maintained within acceptable levels. UARS maintained a controlled attitude within the 108 arc-s specification limit for all three axes. ${ }^{2.3}$ However, as it will be shown, this level of control was not sufficient enough to prevent disturbances from impacting science instrument measurements.

An overview of the instrument and spacecraft response interactions is shown in Fig. 2. Six subsystems and instruments were gimballed with respect to the instrument mount. All the gimballed instruments generated disturbances as they moved which caused the spacecraft to respond. The typical response was the motion of the two flexible appendages and/or rigid-body motion of the spacecraft. ${ }^{5-7}$ Once excited, the flexible appendages perturbed the line-of-sight pointing of the instruments. Except for HALOE, the instruments had no mcans of correcting thcir pointing to account for vibration. The Halogen Occultation Expcriment (HALOE) instrument elevation and azimuth pointing was actively controlled using feedback from sun sensor measurements. Four instruments were attached to the instrument mount without any gimballing mechanism. Their line-of-sight pointing was a result of the spacecraft orientation. Knowledge of the orientation 


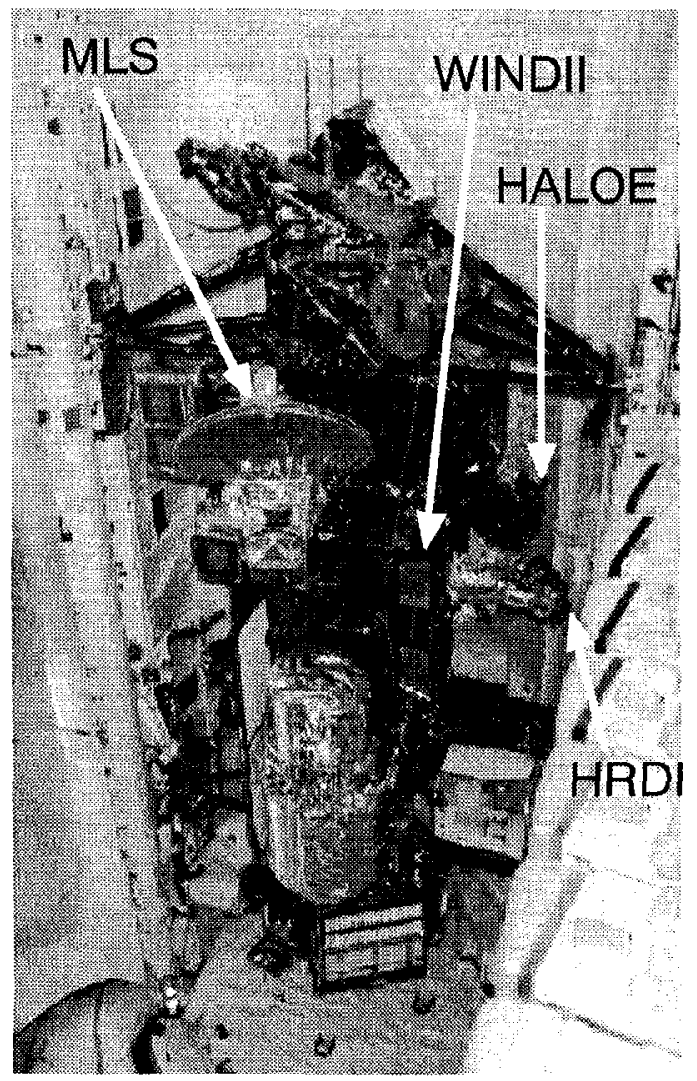

Fig. 1 The WINDII, MLS, HRDI and HALOE instruments on the Upper Atmosphere Research Satellite in the bay of the Space Shuttle Discovery (STS-48).

was provided by the attitude control system. The UARS altitude control system had a number of on-board sensors for attitude determination; however, only the rate gyros in the Inertial Reference Unit (IRU) determined attitude to the precision needed for the three case studies. These gyros had a resolution of 0.05 arc-s. (one telemetry count) and a sampling rate of $7.8125 \mathrm{~Hz}$.

\section{WINDII and HRDI Wind Measurement Correlation with UARS Dynamic Response}

The WINDII and HRDI instruments were used in the first case study. WINDII and HRDI, mounted amidships on UARS, are annotated in Fig. 1. HRDI is also shown in Fig. 3. Many of the HRDI and WINDII science measurements were referenced as field

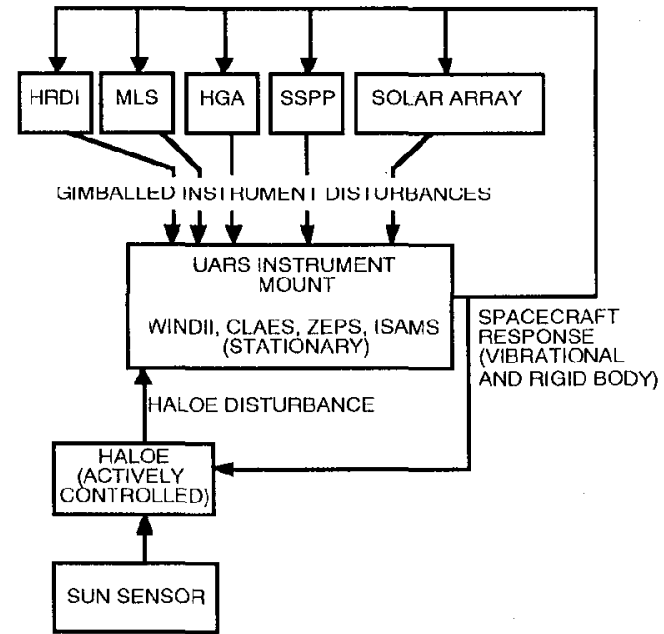

Fig. 2 Interaction of UARS on-board instruments and spacecraft dynamic response.

measurements (i.e., with respect to latitude and longitude). ${ }^{8,9}$ If the vibration of the spacecraft produced a latitude specific signature, the science quantity being measured could be improperly interpreted to have a similar signature. In this section, it will be shown that the impact of jitter could lead to two instruments having different results from the same observed phenomena.

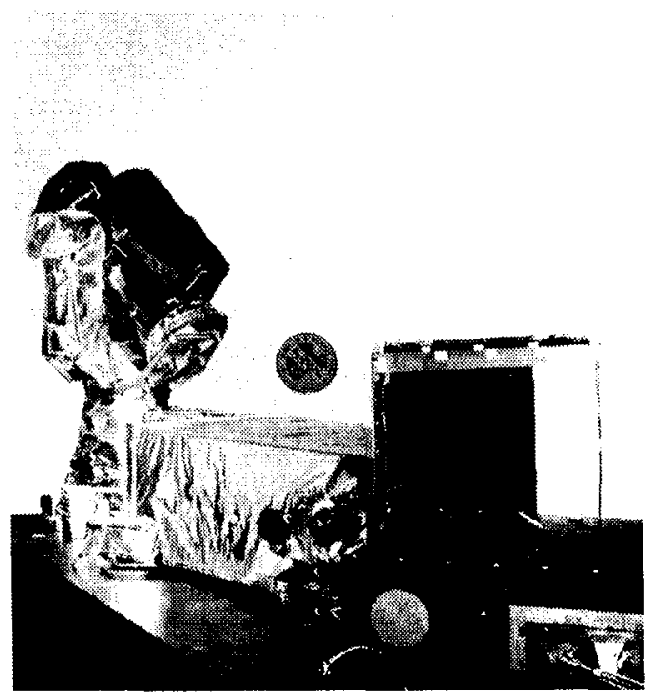

Fig. 3 High Resolution Doppler Imager (HRDI).

HDRI observed the Doppler shifts of spectral lines within the atmospheric band system of molecular oxygen. ${ }^{2.611}$ A triple-Etalon Fabry-Perot interferometer 
served as a high resolution spectral filter to reject continuum cmissions outside the desired absorption lines. The HRDI interferometer was mounted within a two-axis gimballed telescope whose motion was controlled by a microprocessor. The HRDI sequence first measured Doppler shifts while performing a vertical altitude scan in the direction forward of the spacccraft's velocity. The telescope was then rotated 90 deg. and a sccond vertical altitude scan was performed. This scan sequence yielded two measurements over the same region of the atmosphere in a time interval relatively short (less than 7 minutes) compared to the charactcristic time scales for changes in the wind field. Afterward, the scan sequence was repeated. HRDI had one continuous, periodic, open-loop scan profile for the day and a second, shorter-period, open-loop scan profile for the night portion of the orbit. These measurements coupled with knowledge of spacecraft velocity and observation geometry allowed calculations of horizontal vector wind ficlds extending from the upper troposphere through the thermosphere. HRDI measurement requirements imposed a 36 arc-s. limit to spacecraft platform roll displacement over any $0.125 \mathrm{~s}$ time interval (36 arc-s/ $0.125 \mathrm{~s}$ ). UARS dynamic response never exceeded the HRDI pointing requircment.?

The WINDII instrument was not gimballed. The instrument line-of-sight measurements were dependent upon the orientation of the spacecraft. WINDII measured upper atmospheric winds, temperature and emission rate using airglow emission lines photochemically produced using chemical species in the altitude range 80 to $300 \mathrm{~km}$. An imaging field-widened Michelson interferometer was employed to measure small wavelength shifts of the narrow atomic and molecular airglow emission lines induced by the aggregate velocity of the atmosphere carrying the emitting species. ${ }^{2}{ }^{8},{ }^{9}$ WINDII measurement requirements impose a 4 arc-s. limit to spacecraft platform roll displacement over any $2 \mathrm{~s}$ time interval (4 $\operatorname{arc}-\mathrm{s} / 2 \mathrm{~s})$.

Fig. 4 shows mapping of points on UARS' ground track where certain jitter level thresholds werc exceedcd along the roll axis. These mappings used 15 hours of flight data from January 22, 1992. Thresholds were 4 arc-s/2 s (WINDII requirement), Fig. $4 \mathrm{a}$, and $10 \mathrm{arc}-\mathrm{s} / 2$ s, Fig. 4b, respectively. From Fig. 4, it can be seen that the jitter exceeded the thresholds only at cerlain latitudes. The 10arc-s/2 s roll jitter threshold, Fig. 4b, was exceeded at latitudes of $57^{\circ} \mathrm{S}$ due to sunrise thermal snap and at $46^{\circ} \mathrm{N}$ due sunset thermal snap. The bands at $10^{\circ} \mathrm{S}$ and $38^{\circ} \mathrm{S}$ were due to solar array dynamics. In fact, results of Ref. 7 have also shown that UARS jitter response was latitude specific with different response characteristics for forward and backward rotation of the solar array. On January 22, 1992, the solat array was rotating in the forward direction resulting in lower jitter levels.

Results of correlating the HRDI and WINDIl meridional wind speed measurements with spacecraft roll jitter are shown in Fig. 5. Fig. 5a shows points along the UARS ground track where the roll attitude jitter exceeded the WINDII requirement of 4 arc-s during $2 \mathrm{~s}$ measurement windows. The spacecraft was at approximately $26^{\circ} \mathrm{N}$ with the line-of-sight of the HRDI and WINDII measurements at $42^{\circ} \mathrm{N}$. Meridional wind measurements at $40-42^{\circ} \mathrm{N}$ for WINDIl and HRDI instruments are shown in Figs. $5 b$ and $5 c$, respectively. To show the impact of jitter on the WINDII wind measurements, it is necessary to examine the measurements when the WINDIl pointing requirement were not persistently exceeded.

At the longitudes of $70^{\circ} \mathrm{E}-130^{\circ} \mathrm{E}$, the measured jitter were not persistently exceeded along the ground track. In that interval, wind speeds measured by HRDI ranged from $43 \mathrm{~m} / \mathrm{s}$ at $100^{\circ} \mathrm{E}$ to $-62 \mathrm{~m} / \mathrm{s}$ at $130^{\circ} \mathrm{E}$. WINDII measured wind speeds ranged from $30 \mathrm{~m} / \mathrm{s}$ at $90^{\circ} \mathrm{E}$ to 75 $\mathrm{m} / \mathrm{s}$ at $130^{\circ} \mathrm{E}$. There was a $10^{\circ}$ spatial error in the measurements and a $13 \mathrm{~m} / \mathrm{s}$ error in speed. However, at the other longitudes, jitter above 4 arc-s/ $2 \mathrm{~s}$ was persistent throughout the measurement. The spatial and specd error were substantially higher. Except at $-5^{\circ} \mathrm{E}$ and $70^{\circ} \mathrm{E}-130^{\circ} \mathrm{E}$, all wind speeds measured by WINDII are less than $0 \mathrm{~m} / \mathrm{s}$. The wind speeds measured by HRDI were as high as $63 \mathrm{~m} / \mathrm{s}$ (at $-130^{\circ} \mathrm{E}$ and $60^{\circ} \mathrm{E}$ ). Corrclation of HRDI and WINDII meridional wind measurements and spacecraft roll jitter during intervals when the WINDII jitter requirement was exceeded has indicated jitter was the major factor in the measurement disagreement between the two instruments. 


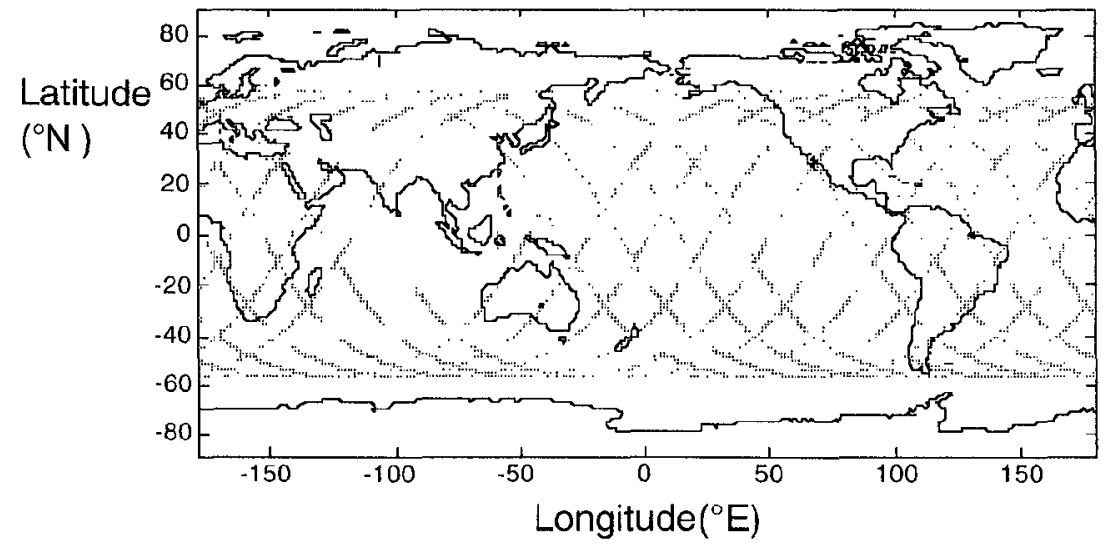

a) Roll jitter exceeding 4 arc-s over a $2 \mathrm{~s}$ interval

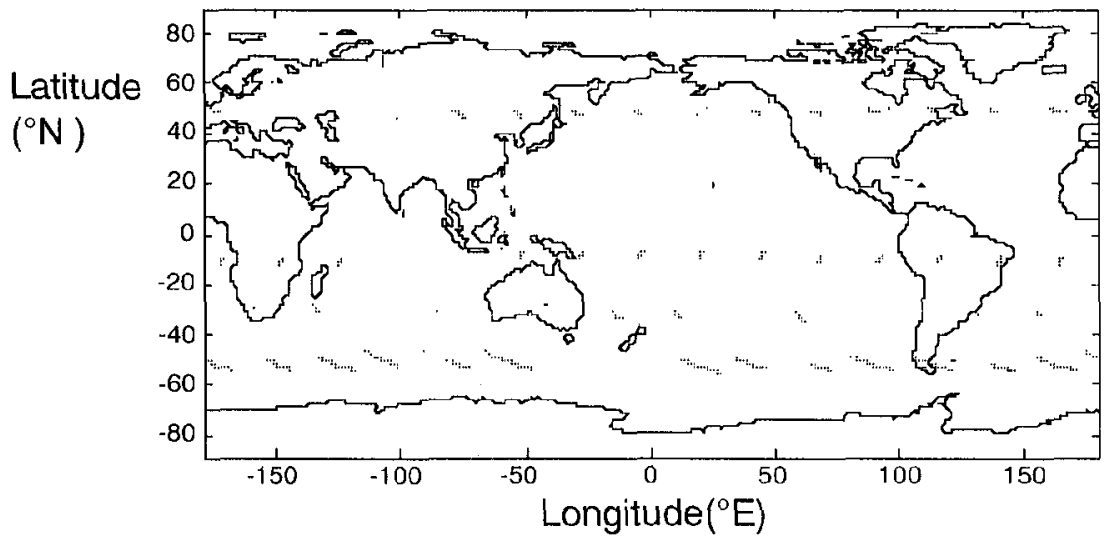

b) Roll jitter exceeding 10 arc-s over a $2 \mathrm{~s}$ interval

Fig. 4 Ground track of roll jitter on Jan. 22, 1992. 


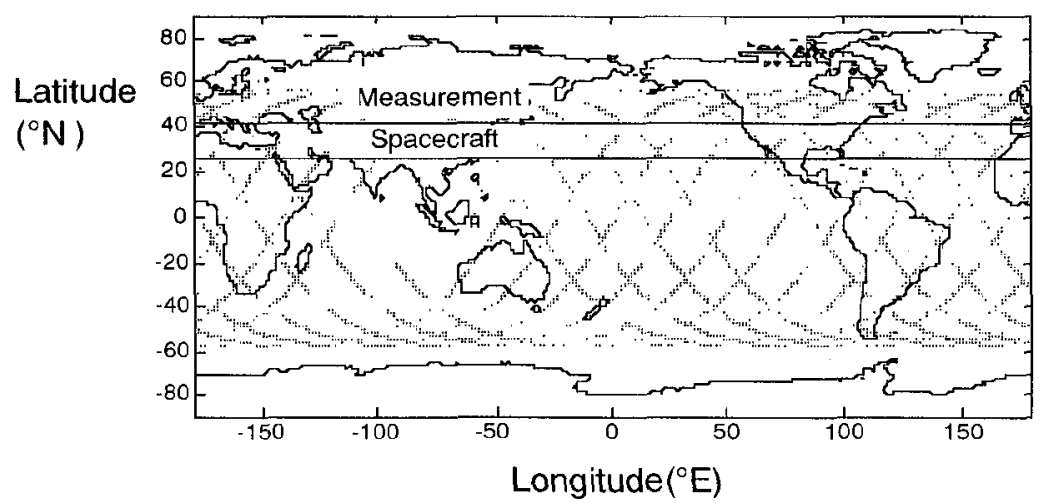

a) Roll jitter exceeding 4 arc-s over a $2 \mathrm{~s}$ interval

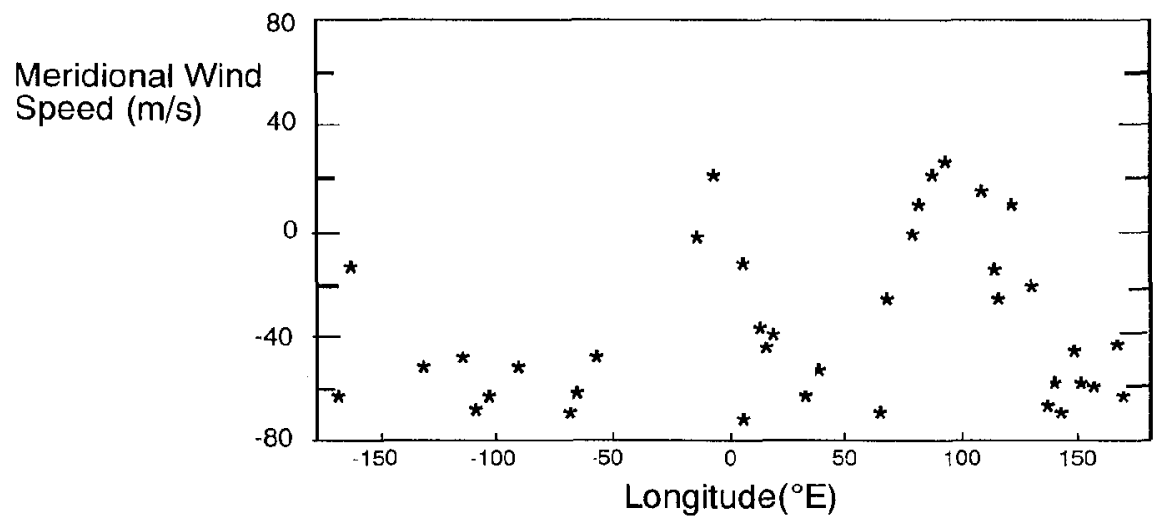

b) Meridional wind speed measured by WINDII, $40-42^{\circ} \mathrm{N}$, at tangent altitude of $97 \mathrm{Km}$.

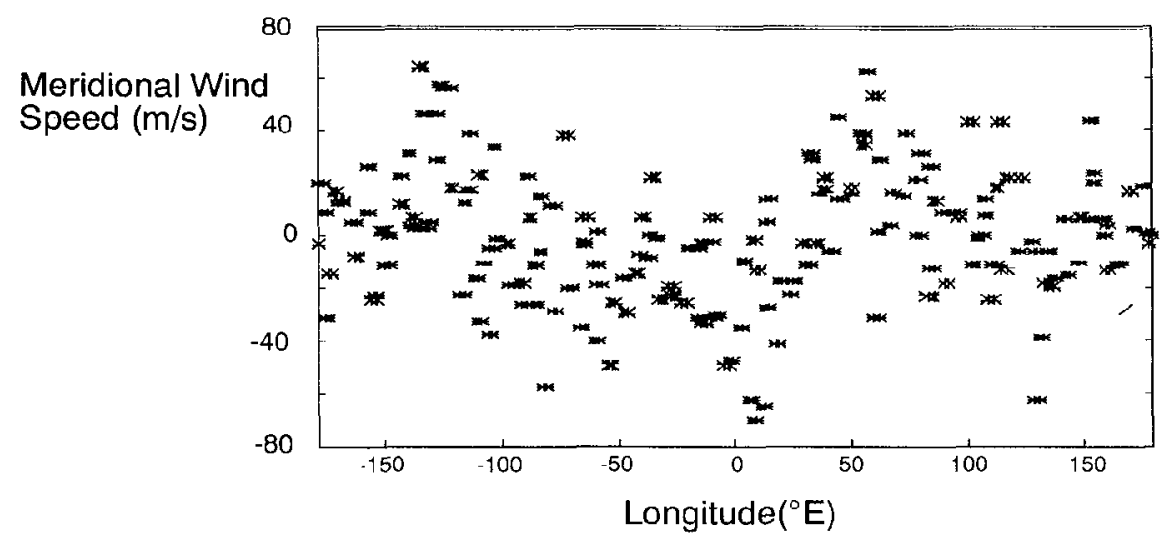

c) Meridional wind speed measured by HRDI, $40-42^{\circ} \mathrm{N}$, at tangent altitude of $97 \mathrm{Km}$.

Fig. 5 Correlation of spacecraft roll jitter with WINDII and HRDI meridional wind speed measurments taken on Jan. $22,1992$. 


\section{MLS Radiance Correlation with UARS Dynamic Response}

On September 17, 1993, an experiment performed on UARS demonstrated the direct effects of spacecraft response on measurements and corroborated the results presented in the last section. For the experiment, the Microwave Limb Sounder (MLS) antenna was controlled such that it maintained a fixed line-of-sight pointing to allow examination of the influence of the spacecraft response on its radiance measurements. MIS is shown in Fig. 6 and annotated in Fig. 1. The fixed MLS line-of-sight pointing emulated the WINDII lineof-sight pointing. MLS had a roll jitter requirement of 18 arc-s/ $2 \mathrm{~s}$, a sampling rate of $0.5 \mathrm{~Hz}$ and spatial resolution of 3-6 arc-s. Thus, MLS had sufficient spatial resolution and sampling interval to discem spacecraft dynamic response.

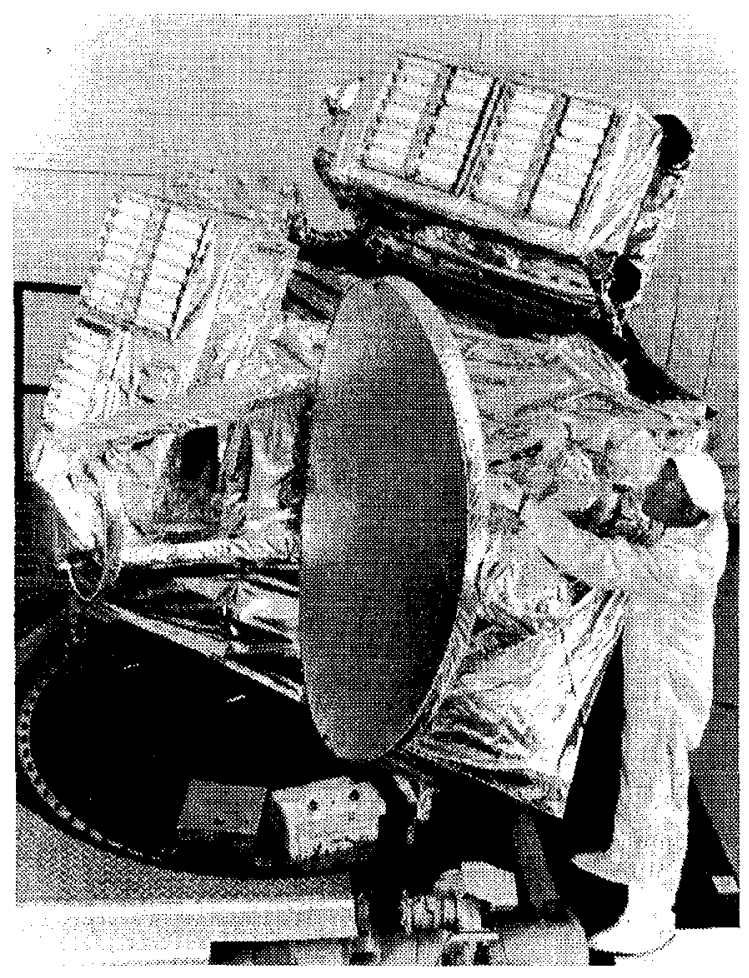

Fig. 6 Microwave Limb Sounder (MLS).

Results of the experiment are shown in Fig. 7. The figure shows the time history of roll jitter and the radiance measurements taken by MLS. Perturbation of the roll attitude resulted in perturbations of the radiance measurements. The disturbances that caused the perturbations are annotated between the figures. The sunset solar array thermal snap produced a pronounced perturbation in the radiance measurement. Sunrise solar array thermal snap produced a noticcable increase in the measured radiance but the perturbation was not as pronounced as that due to the sunset snap. When the solar array stopped and restarted, it resulted in a reduction of the measured radiance. The next stopping of the solar array also resulted in a noticeable reduction of the measured radiance. Except for the sunset snap, the other perturbations could be misinterpreted as actual atmospheric anomaly. However, by corrclating the jitter time history with the radiance time history, the spacecraft response signature can easily be identified. The influence of spacecraft response on MLS radiance measurements corroborated the conclusion that spacecraft jitter was major factor in the WINDII measurements not agrecing with HRDI measurements.

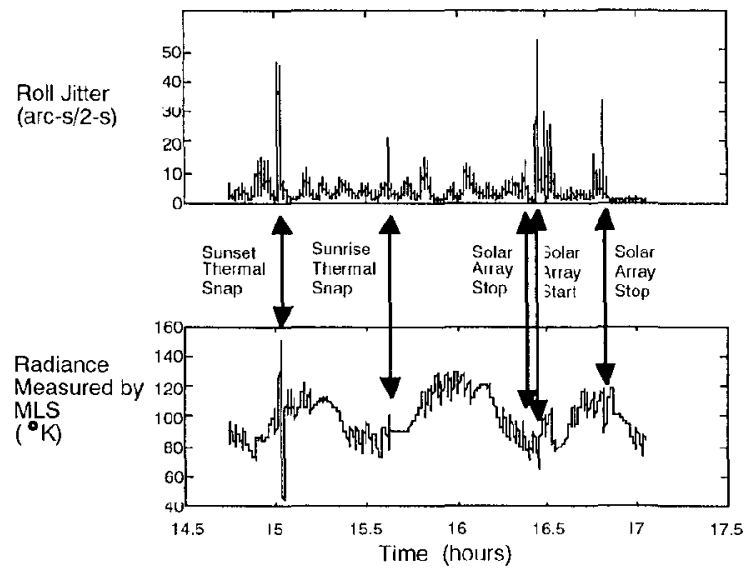

Fig. 7 Spacecraft roll jitter on September 17, 1993 and MLS radiance measurement.

\section{HALOE Measurement Correlation with UARS Dynamic Response}

On May 1, 1992, an experiment performed on UARS demonstrated that the solar array vibration and motion of HRDI perturbed the Halogen Occultation Experiment (HALOE) pointing. ${ }^{6}$ " For the cxpcriment, the Microwave Limb Sounder (MLS) antenna was kept stationary through two successive orbtital sunsets. During the first sunset of the experiment, the HRDI instrument was also kept stationary. During the next sunset, HRDI performed its normal pcriodic 
atmospheric limb-viewing scans. HALOE performed measurements during both sunsets. Comparison of HALOE fine sun sensor (FSS) and $\mathrm{CO}_{2}$ data for the two orbits demonstrated that the HRDI scans perturbed the HALOE FSS measurements.

The HALOE instrument shown in Fig. 8 and annotated in Fig, 1 was mounted amidships on UARS near the HRDI instrument. ${ }^{11,12}$ HALOE measured the vertical distribution of $\mathrm{O}_{3}, \mathrm{HCl}, \mathrm{HF}, \mathrm{NO}, \mathrm{CH}_{4}, \mathrm{H}_{2} \mathrm{O}$, and $\mathrm{NO}_{2}$ over the altitude range from 10 to $65 \mathrm{~km}$ tangent height with vertical resolutions of $2 \mathrm{~km}$. Atmospheric pressure was inferred from absorption measurements of $\mathrm{CO}_{2}$. HALOE used an occultation measurement which required the sun as a light source. Science measurements were taken during orbital sunrise and sunset as the Sun-spacecraft line-of-sight transversed the Earth's limb. The measurement required that the instrument be pointed at the sun during science measurement. A description of the measurement technique can be found in Refs. 11 and 12.

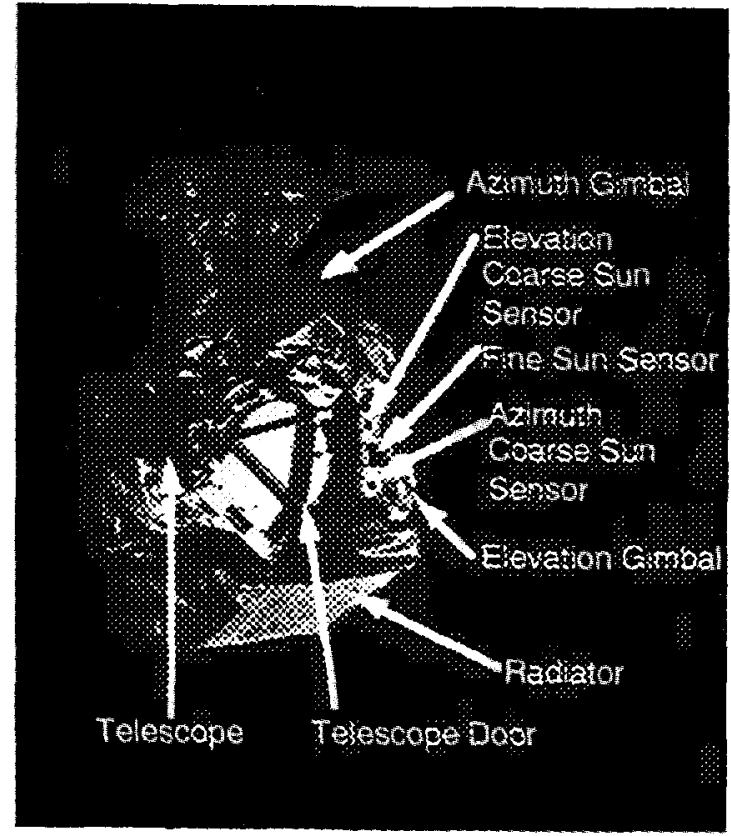

Fig. 8 Features of the Halogen Occultation Experiment.

Instrument pointing must be kept within a specific arca on the solar dise that only extends 120 arc-s in elevation by 360 arc-s in azimuth. A stepper-motor driven biaxial gimbal system, coarse sun sensor (CSS), fine sun sensor (FSS), and a microprocessor-based closed- loop feedback tracking control logic provided the pointing accuracy. Once the sun has been acquired, the FSS provided for solar scanning and tracking. The FSS sampled every $0.016 \mathrm{~s}(62.5 \mathrm{~Hz})$. The control law updated at $0.128 \mathrm{~s}(7.8125 \mathrm{~Hz})$ intervals to keep the maximum misalignment and corresponding track error within one step (16.2 arc-s) after the execution of gimbal motion commands.

During the second sunset of the experiment, HRDI was operating with a scanning frequency of $0.083 \mathrm{~Hz}$. This frequency of $0.083 \mathrm{~Hz}$ was outside the $0.01 \mathrm{~Hz}$ bandwidth of the UARS attitude control system and therefore, entered the spacecraft structure unattenuated by the attitude control system. The response at the HALOE-UARS interface can be observed in power spectral density (PSD) renderings from gyro response measurements. Fig. 9 shows PSDs for roll and yaw gyro time histories. Solar array vibration appears at about $0.25 \mathrm{~Hz}$ and $1.0 \mathrm{~Hz}$. The solar array and HRDI caused motions of a magnitude that can be observed using the HALOE FSS.

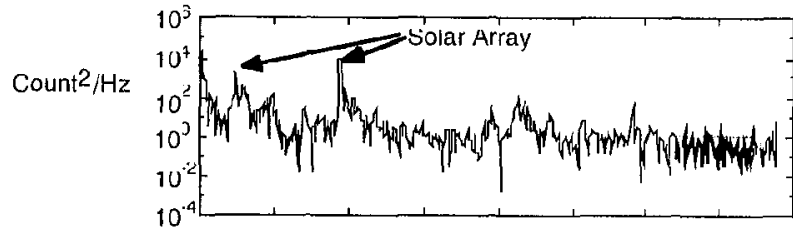

a) Rol:

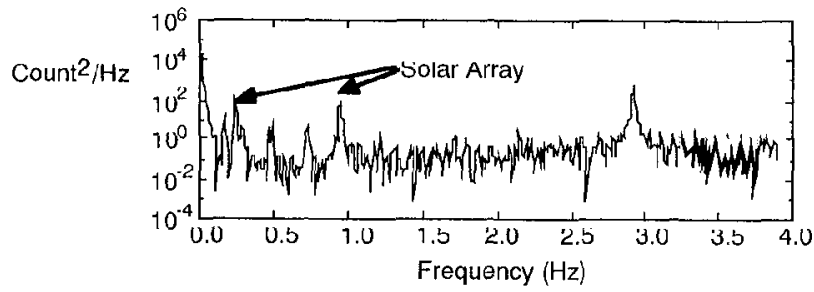

b) YaW

Fig. 9 Power spectral density of UARS rate-gyro tclemetry, May 1, 1992. 1 Count $=0.05$ arc-s.

On May 1, 1992, the solar incidence angle was $2^{\circ}$. The apparent solar motion of 226 arc-s/1 $\mathrm{s}$ was accommodated with gimbal stepping that re-illuminated the FSS reference diode at frequencies of 0.8 and $1.0 \mathrm{~Hz}$. Disturbances in angular position appeared as cyclic additions or subtractions to the apparent solar motion. The cyclic perturbations due HRDI scanning and solar array vibration resulted in a modulation of the frequency

8 
necessary to update the line-of-sight pointing. Fig. 10 shows that the frequencies associated with the disturbances appear as sidebands to the gimbal stepping frequencies of 0.8 and $1.0 \mathrm{H} \%$ However, there is a significant difference between the banding patterns in Fig. 10a and $10 \mathrm{~b}$. These traces represent successive orbits. The difference is in operation of the HRDI instrument. Fig. 10a was during the sunset with HRDI stationary and Fig. 10b was during the sunset with HRDI scanning at a frequency of $0.083 \mathrm{~Hz}$. Differences between the two traces (i.e. the absence of the two annotated side bands) represents the HRDI contribution at $0.083 \mathrm{~Hz}$ to the spacecraft dynamic response. These sidebands appear as frequency peaks $0.083 \mathrm{~Hz}$ away from the frequencies associated with re-illumination of the reference diode. During the solar event which resulted in the PSD of the FSS diode time history represented in Figure $10 \mathrm{~b}$, diode re-illumination occurred at both 0.8 and $1.02 \mathrm{~Hz}$. The peak at $0.720 \mathrm{~Hz}$ corresponds to a modulation first lower side band from $0.8 \mathrm{~Hz}$ (reference diode re-illumination ratc) $-0.083 \mathrm{~Hz}$ $($ HRDI frequency $)=0.717 \mathrm{~Hz}(0.720 \pm 0.01525 \mathrm{~Hz}$ (spectral resolution)); similarly, the peak at $1.076 \mathrm{~Hz}$. corresponds to a modulation first higher side band at $1.02 \mathrm{~Hz}+0.083 \mathrm{~Hz}=1.103 \mathrm{~Hz}(1.076 \pm 0.01525 \mathrm{Ilz}$ (spectral resolution)).

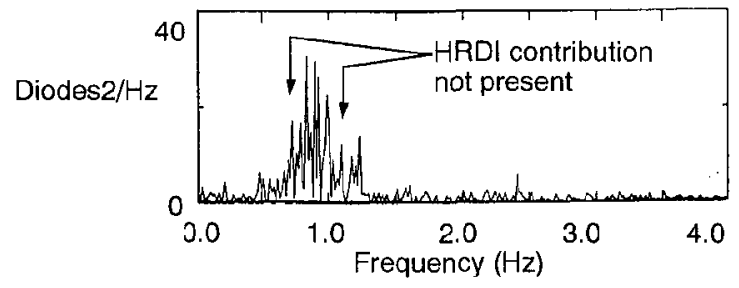

a) HRDI is stationary

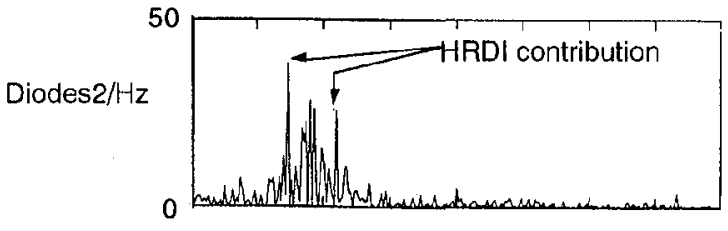

j) HRDI in night scan mode

Fig. 10 Power spectral density for HALOE FSS telemetry data, May 1, 1992. 1 Diode= 16.2 arc-s.

Figs. $11 \mathrm{a}$ and $11 \mathrm{~b}$. show the $\mathrm{CO}_{2}$ measurements during the successive orbits shown in Fig. 10. The absence of high frequency variations in the measurements demonstrated that the active control system eliminated the influence of the spacecraft response and the HRDI night scan on the $\mathrm{CO}_{2}$ measurements. HALOE FSS and $\mathrm{CO}_{2}$ measurements provided the best case for comparing the spacecraft dynamic influence on measurements taken from an actively controlled sensor and a passive sensor. Although, both sensors were on the same gimballed assembly with the same line-ofsight pointing, the FSS sampled the solar disk 7 times between the pointing corrections. IIence, the FSS was able to measure the influence of the spacecraft and HRDI motion on the solar disk measurements. Because the FSS line-of-sight pointing was updated periodically by the HALOE control system, the periodic response of HRDI and the spacecraft were modulations to the FSS control pointing corrections. The $\mathrm{CO}_{2}$ measurements were taken after pointing corrections thus eliminating any influence due to the spacecraft response. Although the active control system removed all adverse effects duc to jitter in the $\mathrm{CO}_{2}$ measurements, the higher sampling rate of the FSS allowed the measurement of the jitter.

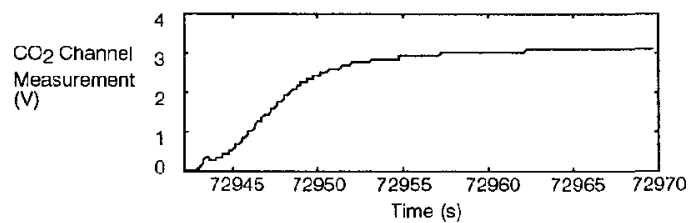

a) HALOE $\mathrm{CO}_{2}$ measurements during HRDI quicscent

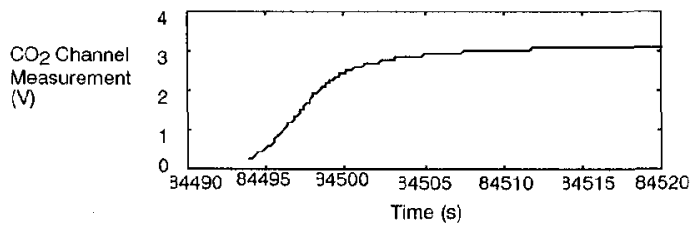

b) HALOE $\mathrm{CO}_{2}$ measurements during HRDI night sean

Fig. 11 HALOE $\mathrm{CO}_{2}$ Masuresurements on May 1, 1992.

\section{Concluding Remarks}

Results have been presented from three case studies using the Upper Atmosphere Research Satellite (UARS) which demonstrated the impact that spacecraft dynamic response had on the subsequent science measurements and analyses. Correlation of the High Resolution Doppler Imager (HRDI) and the Wind Imaging Interferometer (WINDII) meridional wind measurements and spacecraft roll jitter during intervals when the

9 
WINDII jitter requirement was exceeded indicated that jitter was the major factor in the wind measurement disagreement between the two instruments. Further, an experiment performed on UARS on September 17 , 1993, demonstrated that the spacecraft dynamic response directly influenced the Microwave Limb Sounder (MLS) radiance measurement. The influence of spacecraft dynamic response on MLS radiance measurements corroborated the conclusion that spacecraft jitter was the major factor in the WINDII measurements not agreeing with HRDI measurements. Analysis of the Halogen Occultation Experiment (HALOE) fine sun sensor (FSS) demonstrated that when instruments track a target with pointing corrections at discrete intervals, the periodic spacecraft vibration and periodic motion of other instruments is not apparent in the time domain but is revealed in the frequency domain. The influence of the disturbances appeared as frequency modulations of the pointing update frequencies. Comparison of HALOE FSS and $\mathrm{CO}_{2}$ measurcments demonstrated the influence that spacecraft response has on measurements taken from an actively controlled sensor and a passive sensor with the same line-of-sight pointing.

In summary, the three case studies have demonstrated various ways that spacecraft dynamic response impacts science measurements. Furthermore, if the vibration of the spacecraft produced a latitude specific signature, the science quantity being measured could be improperly interpreted to have a similar signature. Therefore, this paper has demonstrated the necessity of examing the vibration response as well as the measurements taken from orbiting satellites.

\section{Acknowledgments}

The authors extend their appreciation to the following people for their assistance and support. From the NASA Langley Research Center: William L. Grantham, Jerry Newsom, John G. Wells Jr., Sudha M. Natarajan, Janet L. Barnes and Jessica Woods-Vedeler. From Bionetics Corporation: Ansel J. Butterfield. From University of Michigan: Mark Burrage. From the Lockheed Martin Astrospace Division: Richard Quinn, Anthony Camello and George Futchko. From the Jet Propulsion Laboratory: Evan Fishbein and Robert Jarnot.

\section{References}

${ }^{1}$ Grantham, W. L., "NASA Future Mission Needs and Benefits of Controls-Structures Interaction Technology," NASA TM 104034, Jan 1991.

${ }^{2}$ General Electric Company Astro-Space Division, "Upper Atmosphere Research Satellite Project Data Book," NASA Goddard Space Flight Center, April 1987.

${ }^{3}$ General Electric Company Astro-Space Division, "Upper Atmospherc Rescarch Satcllite Command and Telemetry Handbook," SDS-4219, January 1991.

${ }^{4}$ Trevathan, C. E. and Burr, P. T. "Mission Requirements Document for the Upper Atmosphere Research Satellite," NAS^ Goddard Space Flight Center Document 430-1601-001, Sept. 1984.

5 Molnar, J. and Garnek, M., "UARS In-Flight Jitter Study for EOS," NASA CR 191419, Jan 1993.

${ }^{6}$ Butterfield, A. J. and Woodard, S. E., "Measured Spacecraft Instrument and Structural Interactions," Journal of Spacecraft and Rockets, Vol. 33, No. 4, July-August, 1996, pp. 556-562.

7Woodard, S. E., Lay, R., Jarnot, R., Gell, D., "Experimental Investigation of Spacecraft In-Flight Disturbances and Dynamic Response," Accepted for publication in the Journal of Spacecraft and Rockets, A10222.

${ }^{8}$ Shepherd, G. G. et al, "WINDII, The Wind Imaging Interferometer on the Upper Atmosphere Research Satellite," Joumal of Geophysical Research, Vol. 98, No. D6, June 1993, pp. 10,725-10,750.

${ }^{9}$ Shepherd, G. G. et al, "Longitudinal Structurc in Atomic Oxygen Concentrations Observed with WINDII on UARS," Geophysical Research Letters, Vol. 20, No. 12, June 1993, pp. 1303-1306.

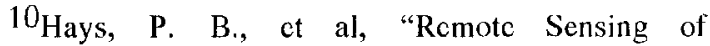
Mesospheric Winds with the High-Resolution Doppler Imager," Planetary and Space Science, Vol. 40, No. 12, 1992, pp. 1599-1606.

11 Keafer, L. S., et al, "Halogen Occultation Experiment Instrument Description Document," HALOE-02-028C, NASA Langley Rescarch Center, Oct. 1988.

12 Mauldin, L. E., Moore, A. S., Stump, C. W., and Mayo, L. S., "Digital Solar Edge Tracker for the Halogen Occultation Experiment," Optical Engineering, Vol. 26, No. 6, June 1987, pp. 513-519. 
Copyright (C1997, American Institute of Aeronautics and Astronautics, Inc.

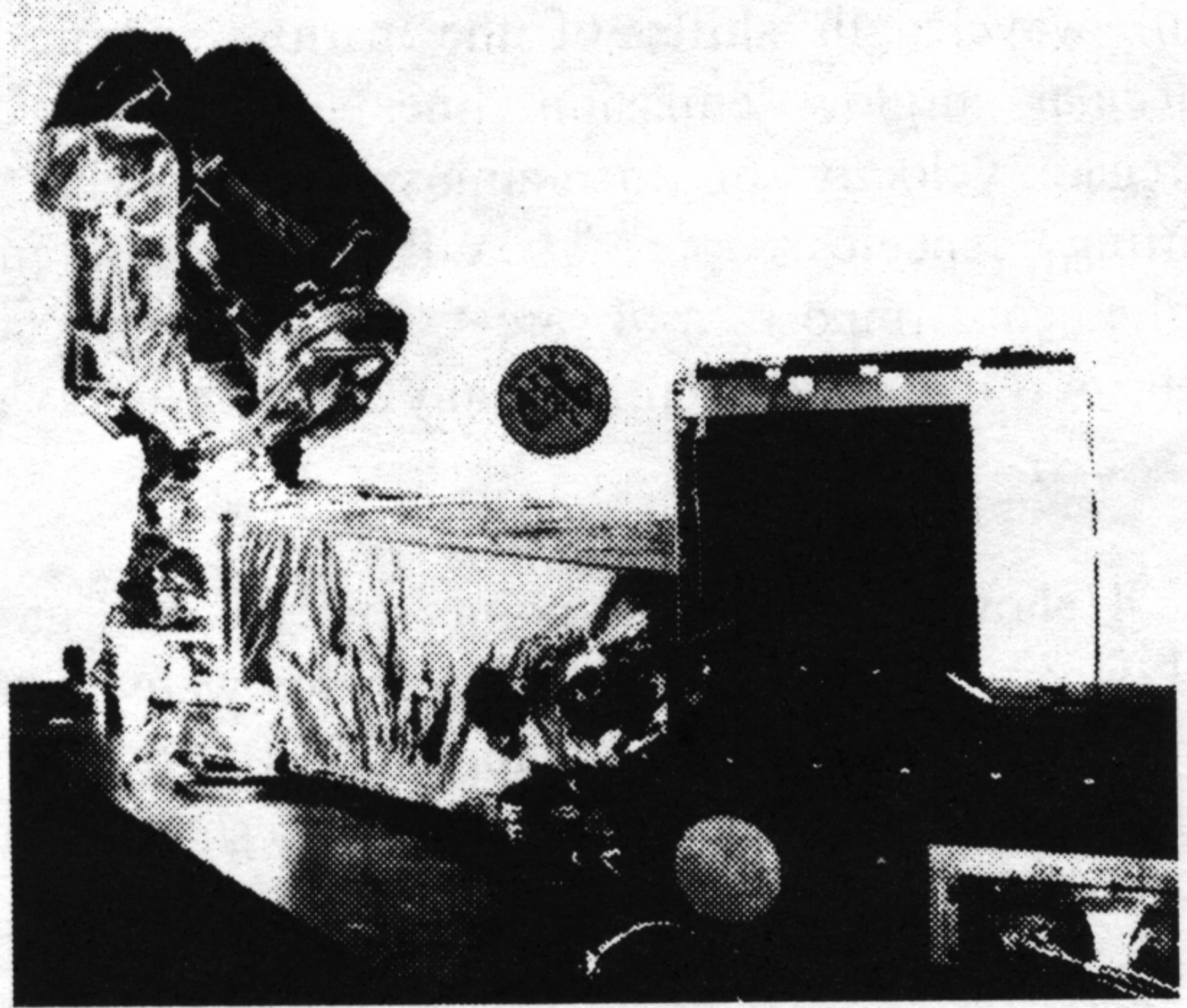

Fig. 3 High Resolution Doppler Imager (HRDI). 


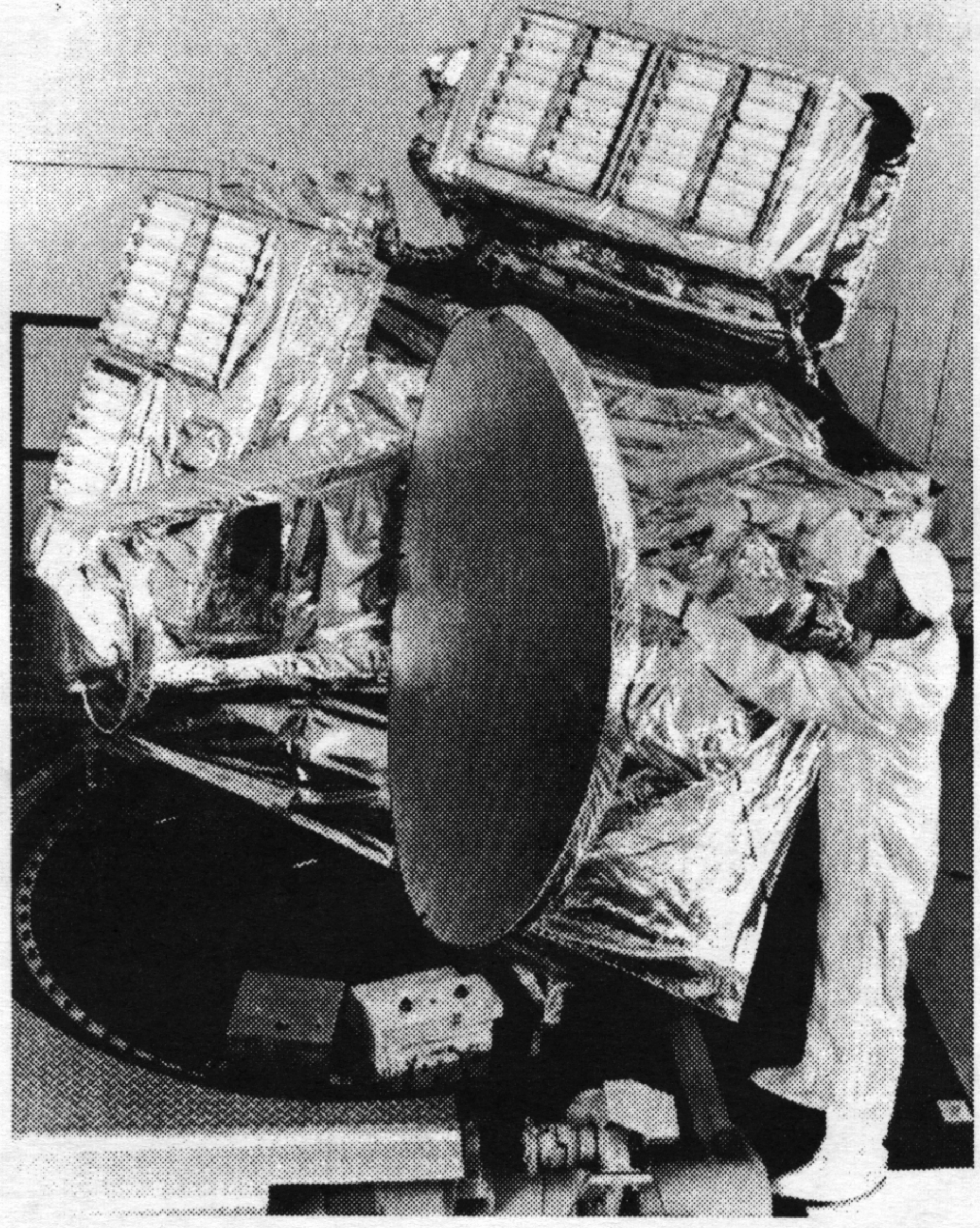

Fig. 6 Microwave Limb Sounder (MLS). 


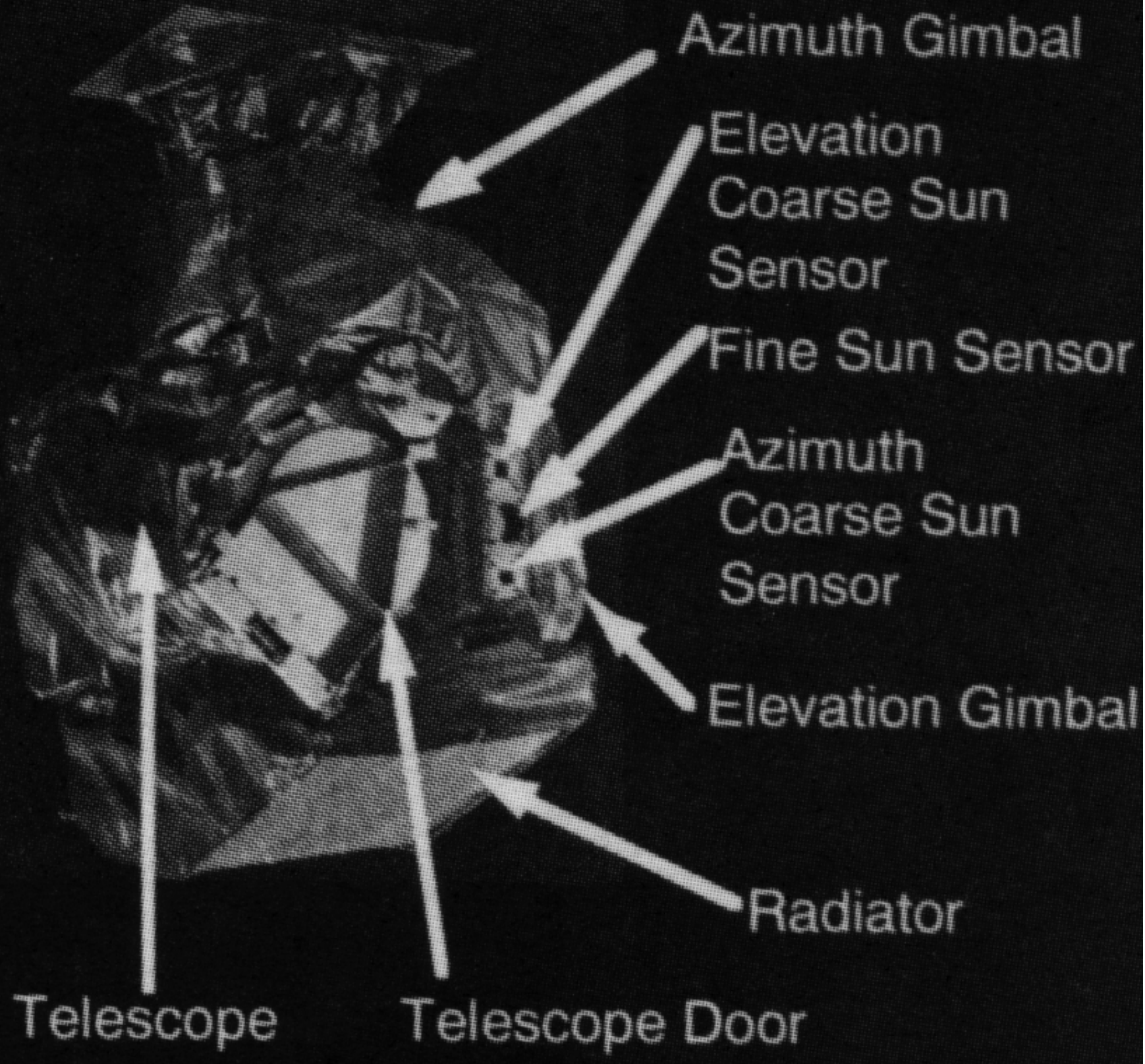

Fig. 8 Features of the Halogen Occultation Experiment. 